\section{GUARD AGAINST ACID EROSION}

BioRepair toothpaste contains a unique MICROREPAIR formula that is similar to the main component of enamel. It penetrates into the tiny cracks, dissolving and binding with the tooth enamel and dentine to help repair the teeth.

BioRepair toothpaste protects and strengthens teeth and fights sensitivity and is designed for use every day by the whole family. Biorepair Plus Sensitivity Control Toothpaste does not contain any fluoride therefore it can be used by children aged under seven. New Biorepair

\section{BRUSH FUN FOR WILD KIDS}

Flipper is the fun way to encourage children to use their toothbrush regularly. A toothbrush holder that attaches to bathroom mirrors, tiles or any shiny surface with a suction cup, Flipper comes in five different animal characters from the 'Wild Family' range, all of which will bring a smile to tired faces in the morning and at bedtime.

As your child takes hold of the toothbrush handle and pulls, the cover will simply flip open, and when returned Flipper will close on itself, keeping the toothbrush tidy and protecting the bristles.

Flipper toothbrush holders prevent cross contamination of bacteria from storing the whole family's toothbrushes in one pot. Toothbrushes can
Repair and Protect contains Biomimmetic Fluorapatite, an inorganic fluorapatite with no active free fluoride ions, so it is not ingested into the body.

All BioRepair toothpastes will help protect enamel and guard against acid erosion with daily use.

Reader response number 58

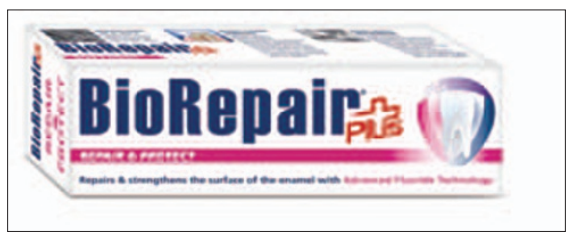

also pick up germs when the toilet is flushed, through tiny water droplets in the atmosphere.

Reader response number 59

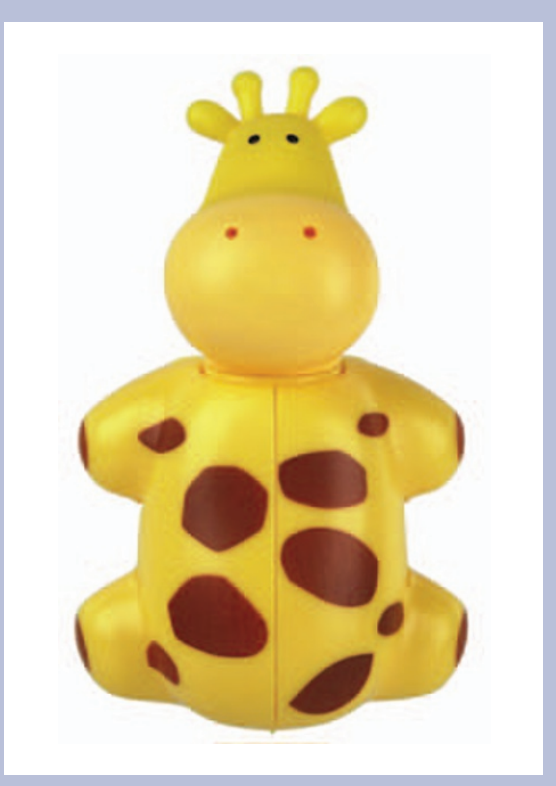

\section{NON-DISRUPTIVE} REFURBISHMENT

If one of the main concerns when considering a practice refurbishment is the disruption of treatment, Tavom prides itself on transformations with minimal disruption. As notoriously busy people practice principals can spare very little time considering refurbishment options, having to diligently concentrate on the job in hand. However, an ineffective workspace can have an adverse effect on the daily performance of staff, and subsequently the well being of the patient.

Since 1975, Tavom has been providing bespoke dental cabinetry solutions that have earned international acclaim. Complete dedication to excellence means that expert consultants and highly skilled engineers work with practitioners from initial design to final installation, ensuring receipt of the very best innovative solutions to individual requirements.

Superior materials provide aesthetically compatible cabinetry, and nonporous, durable work surfaces of Corian or glass offer practicality.

Tavom perfectly balances style, ergonomics and value, providing cost-effective bespoke cabinetry solutions.

Reader response number 60

\section{INGENIOUS LATEST MODEL}

Oral-B is proud to introduce the newest model of Oral-B Triumph - already a highly sophisticated toothbrush with the Oral-B Triumph 5000 with SmartGuide.

Communication is key to patient compliance and that is why this ingenious model has six innovations to help motivate your patients to brush for longer, without applying too much pressure. A new visible pressure indicator on the reverse of the handle lights up when too much force is applied, and an override mechanism within the unit automatically reduces the brushing speed and stops the pulsating motion of the brush. To coincide with this, an icon on the SmartGuide (the wireless LED remote device) alerts the patient that they're brushing too hard.

To ensure patients pay equal attention to all areas of their mouth, the new Triumph 5000 now incorporates an audible timer which beeps after 30 seconds, alerting the user that's it's time to focus on the next quadrant. The concept of cleaning by quadrant is further reinforced by a new star reward function on the SmartGuide that gets filled in every 30 seconds, so patients can see for how much longer they must clean their teeth. The SmartGuide also has simplified icons to indicate which of the four different brushing motions are being employed.

On the front face of the handle there's now a convenient LED display that indicates whether the brush is fully charged as well as new illuminated 'on/ off' and 'mode' option buttons.

Reader response number $\mathbf{6 1}$

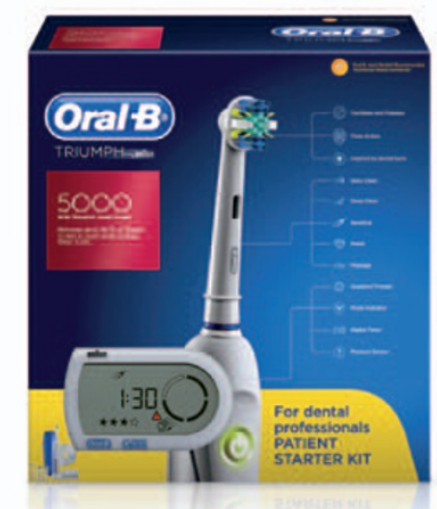

